\title{
HISTORY OF TWO CASES
}

\author{
or \\ ANGINA PECTORIS.
}

BY SAMUEL BLACK, M.D.

OF NEWRY.

COMMUNICATED BY

DR. CURRY.

Read Jan. 23, 1816.

AT the time when my first observations on the disease which has been named Angina Pectoris*, were communicated to the public, the affection was by no means so well understood, nor the morbid changes of structure on which it appears to depend so thoroughly investigated and ascertained as they have since been. Many zealous and diligent inquirers have communioated to the medical world the result of their observations on this subject; but the learned and truly didactic work of Dr. Parry of Bath, has concentrated into one luminous point of

- The first of my papers is contained in the Fourth Volume of the Memoirs of the Medical Society of London, and was read to that Society, in March 1794; the second (Vol. VI.) was read in October, 1796. 
view the scattered rays flowing from a variety of sources. I have, in the course of subsequent experience, met with two additional cases of this disease, in both of which, I have had an opportunity of ascertaining by dissection, the moibid changes of structure ; and their coincidence with those formerly detailed, is so remarkable, that I trust the Society will consider the accumulated weight of evidence as worthy of being communicated to the public. It occurs to me that there are few diseases in which the morbid changes may be predicted with greater confidence.

The first of the two cases which I have now to notice, was that of Mr. Marron, an eminent schoolmaster, of this place, who, at the period of his death, was aged about 56 . The circumstances of this case I must detail partly from memory, and partly from some short notes which I find in an old common-place book of that day. A history of the disease and of the appearances on dissection which I had drawn up was destroyed by a sinister accident. Mr. Marron had been through life a healthy man, not liable to gout, nor indeed to any other disease. He had, howerer, been exposed to bitter domestic affliction, having, by a consecutive train of calamity, lost a number of fine children, till at last he was left childless. His disease commenced in 1799. The first symptom was an intolerable sense of anguish under the sternum, seizing him while walking, especially if up hill, or at a pace at 
all accelerated; accompanied by a severe pain diffusing itself from the chest to the left scapula, and down the left arm to near the elbow. The sensation was such as to impress him with an apprehension, that if he should advance another step, life would be extinguished. But on standing still, these symptoms immediately vanished. When matters had gone on in this way for nearly eighteen months, he began to be awaked out of sleep, by the nightly paroxysms. These admitted of a temporary and imperfect relief from opiates and cordials. About September 1803, he began to have decided indications of hydrothorax. These were repeatedly relieved by digitalis, squill, and the pil. hydrarg. ; but uniformly recurred after a short interval. In a word, he spun out life in this miser. able way till July 1804, when he expired rather suddenly.

\section{The Dissection.}

Permission being obtained to open the body, the first striking appearance was the degree to which the cellular membrane was loaded with fat. The cartilages by which the ribs are connected with the sternum, had become completely osseous. The cavity of the chest contained a large quantity of fluid. The heart was loaded with fat, large, flabby, and soft. The valves were all sound. There were several osseous scales on the internal surface of the aorta, near its origin. The coronary arteries (which are still in my possession) were ossified through their whole extent. 
The second case which I have to narrate, was that of a lamented friend, the Rev. Joseph M'Cormick, many years vicar of Aghaderg, in the diocese of Dromore, but lately promoted to the rectory of Mealiff, in the arch-diocese of Cashel. Mr. $M ` C o r m i c k$ was aged about 56 , had been occasionally affected with gout, but neither frequently nor severely. He had been liable for many years to discharge of blood from the hæmorrhoidal vessels, without pain or external tumour. This had often been profuse, but had entirely ceased for three years or more, and he had become fat and rather plethoric. All his habits were those of the strictest regularity and temperance, and he was uniformly influenced by those principles of virtue, honor, and worth, that adorn and exalt the human character,

I visited him early in the month of January last, when I was enabled to ascertain the following circumstances.

Mr. M`Cormick had undergone much fatigue and anxiety during Christmas week, in visiting his parishioners for the last time, preparatory to his removal to the south of Ireland. On Christmas-day, he preached his farewell sermon. The emotions to which this gave rise on both sides were of a very warm and lively character, commensurate with the ardor of esteem and attachment subsisting between him and his flock. The peculiar services of the day were protracted to an unusual length, by which 
he was much fatigued. His glebe-house was distant from his church about half a mile, and between them was a gentle acclivity. While ascending this, he was obliged suddenly to stand still on account of a feeling of exquisite distress in the chest, accompanied by such a sense of debility and sinking, as appeared to threaten instantaneous dissolution. When he stood still, these feelings immediately subsided; but were repeatedly renewed by renewed attempts to continue his walk. At length he got home with difficulty, and in a state of great exhaustion. This paroxysm was very easily reproduced ever afterwards, by very slight muscular exertion; such as walking up stairs, dressing or undressing, going into the tepid bath, \&c. was uniformly accompanied by a very painful sensation, to which he applied the term scalding, diffusing itself from the left side of the thorax towards the scapula, the osophagus, and down the left arm to the insertion of the deltoid muscle, where it terminated.

It appeared to me altogether extraordinary, that this complaint should have risen to such an intensity in so short a time. However, on making minute inquiry, I found that he had occasionally been affected with feelings of the same kind for a length of time, perhaps three or four years, but that they had never assumed the same exquisite form as since Christmas-day. He had long been unable to walk up a hill, or against a strong wind, without baving some degree of this peculiar anguish excit- 
ed in the chest. He had, however, partly from his uncomplaining disposition, and partly from a reluctance to give alarm to his family, forborne to say much on the subject. I found farther, that he had for many years been prone to faint, more especially after dinner. His pulse was from 50 to 56, and weak. In the month of February he began to be attacked out of sleep by the nightly paroxysms.

From the distance of his residence, I had no opportunity of seeing him during the paroxysm; but he told me that his feelings on these occasions were as if every thing within were at a pause, or as if he rere just going to die. It is deserving of attention, that, on many occasions, he was able, by getting out of bed, fixing himself in his arm-chair, and concentrating his attention on some interesting kind of reading, to baffle the paroxysm, as he expressed it. He also found relief from making a moderately full inspiration, retaining the breath and keeping the chest for a time in that state of expansion. He thought himself at all times the worse for eating, however moderately, and he had an unpleasant sensation both in manducation and deglu. tition, which indisposed him to the exercise of those functions.

In the month of March, the symptoms of hydrothorax were unequivocally marked, and the ancles became cedematous. These symptoms were effec- 
tually relieved, for a time, by the digitalis and pil. hydrarg.; but they soon recurred; Towards the latter end of May, he went to Dublin, where he remained for some time under the care of Dr. Edward Percival, Dr. Mills, and Mr. Richards. About the 21st of June, he returned from Dublin to Rostrevor. The cellular membrane was now universally loaded with effused fluid, and the symptoms of hydrothorax so very urgent, that he could rarely get into the recumbent posture at all; and after infinite suffering and distress, sustained like a philosopher and a Christian, he expired on the morning of Thursday the 13th of July.

\section{The Dissection.}

The good sense and enlightened humanity of his friends anticipated my anxious wishes, and suggested to them the propriety of examining the body. 'That operation was performed in my presence, thirty hours after death, by Mr. Brown, staff-surgeon. On turning back the integuments, the cellular membrane was more loaded with fat than I had expected. On attempting to cut through the cartilages by which the ribs and sternum are connected, they were found so completely bony that the knife would make no impression on them, and Mr. Brown was obliged to use a small saw for that purpose. On laying open the cavity of the thorax, there appeared a very large effusion into the sacs of the fleura, to the amount of at least eight or nine pounds. 
The pericardium did not partake of this effusion. The heart, considerably loaded with fat, was large, flaccid and tender, and deficient in that floridness which the healthy heart possesses. On its external surface, were several spots of the breadth nearly of a sixpence, of a palish yellow colour, but perfectly soft. The valves were all sound. The coronary arteries were ossified in a remarkable manner. They are in my possession. One of them divides, immediately after its origin, into three principal branches, every one of which is osseous through its whole extent: saving that the bony structure is interrupted at intervals. The longest branch, which is five inches long, is not pervious to the smallest probe for more than half an inch; the other two branches not so far. The other coronary does not divide into branches, but its calibre is perfectly obliterated, and they are all as rigid and incompressible as any other bone of the same diameter. About three inches of the aorta being cut out, its internal surface exhibits a number of osseous scales, surrounding more especially the origin of the coronaries. There is one very remarkable la. mina of bone, one-third of an inch long, nearly as broad, and as thick as a shilling.

The lungs were perfectly sound, as were the abdominal viscera. Some adhesions between the omentum and the concave surface of the liver could not be said to form an exception. 
I do not think it necessary (for it could not be useful) to trouble the Society with any detail of the treatment employed in these cases. It was, unfortunately, perfectly ineffectual. But I can refer, with great confidence, to Dr. Parry's work, already quoted, as containing the best and fullest instructions on this head that the present state of our knowledge admits of. I beg leave also to mention, with much approbation, a synoptical view of the subject given by Dr. Blackall, of Exeter, at the end of his Book on Dropsy. I shall, however, take the liberty of offering a few general remarks, which appear to me deserving of some attention.

1st. Of my four patients, one only had been liable to gout.

2ndly. Of the four cases, two terminated by a copious effusion into the chest; one by an effusion into the pericardium, and one without any effusion. 'This effusion is to be regarded as a mere effect or consequence of the original disease.

$3 r d l y$. In every one of the four cases, there was an ossification, more or less complete, of the cartilages of the ribs. This circumstance is curious. It would almost indicate the existence of an ossific diathesis, (if I may use that expression) shewing its influence beyond the limits of the arterial system. 
4thly. The disease appears in general to be connected with a full habit, and an accumulation of fat in the cellular membrane. It may perhaps, in some instances, have some connexion with suppressed discharges. $\mathrm{Mr}$. M'Cormick had, for a series of years, been liable to a bleeding from the hæmorrhoidal vessels, which had ceased for three or four years. But whether the cessation of this discharge and the commencement of the angina pectoris stood to each other in the relation of cause and effect, I shall not take upon myself to decide. The late Dr. Smyth, of Dublin, attributed the successful issue of one of his cases to large spontaneous discharges of a gleety ichor from the scrotum and anus.

5thly. From the statements in the last paragraph, the propriety and expediency of issues would seem to follow as a natural consequence. In Mr. Carson's case* they had, for a time, a very beneficial operation. But in Mr. M`Cormick's case, they were tried without advantage, as well as in $\mathrm{Mr}$. Woodney'st.

6thly. It has been alleged, that the ossification of the coronaries should be regarded as the consequence, not the cause of the disease. It appears to me, that a controversy on this head would partake of the nature of a verbal dispute. If the ossification

* Medical Memoirs, Vol. VI.

+ Ibid. Vol. IV. 
of the coroparies be an effect of the disease, then we must look for the cause in that diseased action of these arteries, (whether it be of the nature of inflammation or of spasm, or some other specific action different from either) by which osseous matter is deposited in their coats; and thus we merely trace the chain of causation one link higher, without adding to our knowledge.

7thly. I think there is a foundation for Dr. Parry's classification of this disease under the genus Syncope. I have stated that Mr. M'Cormick had for several years been liable to occasional faintings, and certainly the paroxysm seems to consist very much in an impediment or suspension of the vital action of the heart.

8thly. I have stated it to be my opinion*, that the primary and original cause of this disease, is, perhaps, in every instance an ossification of the coronaries. This proposition is perhaps too general, and some qualification of it may be more reconcileable with the reserved spirit of just induction. But if I am permitted to subjoin these words, viz. " or some organic lesion, most usually of an osseous nature, existing at the origin of the circulation," the proposition will then be as true as most others in pathology. It does not appear to me, that the idea thrown out in my first papert, that me-

* Medical Memoirs, Vol. VI.

+ Ibid. Vol. IV. 
chanical pressure alone is capable of producing all the symptoms, - has been at all supported by subsequent experience. The opinion was founded chiefly on the dissection of the body of R. M. Esq. given by Dr. Fothergill *.

9thly. The powerfully pernicious influence of strong mental emotion, or of depressing passion, is strikingly illustrated by the history of $\mathrm{Mr}$. M'Cormick's case. I have no doubt that the foundation of this disease had been laid years ago. But the occurrences of Christmas week, and the prospect of an immediate separation from his. beloved friends and flock, brought it suddenly to a crisis, which I think it would not have arrived at so rapidly, except through the operation of some powerful cause of this kind. It seems deserving of attention also, that Mr. Marron had been, for the latter years of his life, exposed to the influence of a similar cause, grief for the loss of his numerous family; and in Dr. Parr's case, narrated by Dr. Blackall, the patient was seized with his disease immediately after an imprisonment on account of debt.

10thly. There is nothing in the history of this disease more remarkable, or to me more inexplicable, than the exemption of the female sex from its attacks.

* Med. Observations, Vol. V.

VOL. VII. 
11 thly. When we call to our remembrance, that the disease appears in general to have some relation to obesity, or to a plethoric habit,-that the great majority of the subjects of it seem to have belonged to such a rank of society, that we must presume they sat down daily to a plentiful table,- - that every thing which hurries the circulation, or urges the machinery by which that function is carried on beyond its capacity of performance, seems to create, or to favour the tendency to paroxysms; - and lastly, as the hope of a cure from medicine seems (in the present state of our knowledge) very slender, I aṣk, would it be irrational to propose the trial of a regimen as low and abstemious as is compatible with life? I am far from proposing a general rule applicable to every possible case: for something must depend on the constitution and habits of the patient; and much on the discernment and good sense of the physician. Should, however, such a trial be made, undoubtedly it should be on the very first threatening of the disease : for if that be completely established, success could not be expected.

\footnotetext{
"Principiis obsta : sero medicina paratur, "Cum mala per longas invaluêre moras."
}

The systematic pursuit of such a plan, would require a degree of firmness and vigour of mind with which the generality of men are not gifted; and the occasions are numerous on which it may be ex- 
pedient to remember in a medical sense, what Tacitus lays down in a moral one, " Naturâ tamen infirmitatis humanæ, tardiora sunt remedia quam mala."

But should the disease occur in a person so endowed as to be adequate to the trial, he might possibly, under a prudent physician, think it worth his while to try an experiment, the efficacy of which is yet to be ascertained. 